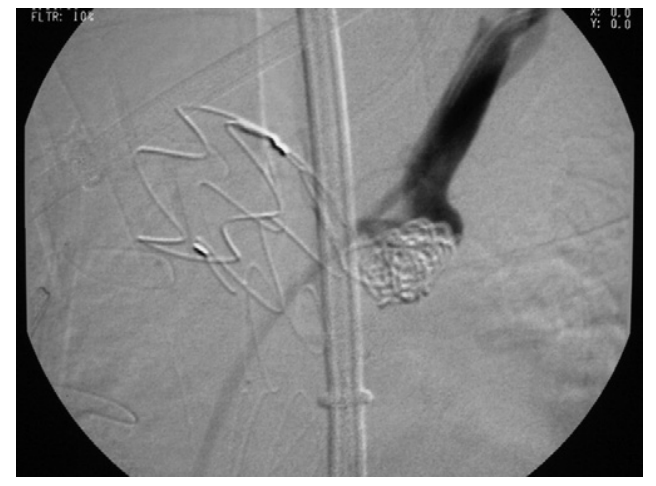

Figure 2. Angiogram showing the coiling of the left subclavian artery.

\section{Discussion}

The successful management of an aortoesophageal fistula remains a challenge. ${ }^{1-4}$ Moreover, therapeutic procedures are even more complicated in patients with a right-sided aortic arch. To date, 3 cases of an aortoesophageal fistula have been described in patients with a right-sided aortic arch, 2 of whom died as the result of a massive hematemesis. ${ }^{1-3}$ In addition to open surgery, endovascular approaches with stent-grafts to treat aortoesophageal fistulas have been described. ${ }^{4,5}$ Although the presented cases thus far underwent open surgery, our patient underwent an endovascular procedure by introducing a stent-graft in the aortic arch after an unsuccessful suture. To our knowledge, this is the first successful endovascular reconstruction of an aortoesophageal fistula in a patient with a right-sided aortic arch. However, the long-term outcome of endovascular therapy remains to be determined, because a recurrent aortoesophageal fistula developed in our patient, necessitating open surgery.

\section{References}

1. Edwards BS, Edwards WD, Connolly DC, Edwards JE. Arterial esophageal fistulae developing in patients with anomalies of the aortic arch system. Chest. 1984;86:732-5.

2. Matsuno $\mathrm{O}$, Matsumoto $\mathrm{T}$, Tsuda T. Aortic aneurysm involving a right-sided arch complicating aortobronchopulmonary and aortoesophageal fistula. Intern Med. 2001;40:722-5.

3. Rodriguez E, Park P, Cowan S, Weinstein M, Kaulback K, Friedberg J, et al. Complicated Management of a traumatic aortoesophageal fistula in a patient with a right sided aortic arch. J Trauma. 2004;56:691-3.

4. Leobon B, Roux D, Mugniot A, Rousseau H, Cerene A, Glock Y, et al. Endovascular treatment of thoracic aortic fistulas. Ann Thorac Surg. 2002; 74:247-9

5. Flores J, Shiiya N, Kunihara T, Yoshimoto K, Yasuda K. Aortoesophageal fistula: alternatives of treatment case report and literature review. Ann Thorac Cardiovasc Surg. 2004;10:241-6.

\title{
Four thymus-related syndromes in a case of invasive thymoma
}

\author{
Marco Lucchi, MD, ${ }^{\text {a }}$ Andrea Viti, MD, ${ }^{a}$ Roberta Ricciardi, MD, ${ }^{\mathrm{b}}$ Luigi Murri, MD, ${ }^{\mathrm{b}}$ and Alfredo Mussi, MD, ${ }^{\mathrm{a}}$ Pisa, Italy
}

T hymoma is an epithelial tumor that is frequently associated with autoimmune phenomena and paraneoplastic syndromes. The most frequent are neuromuscular ${ }^{1}$ and hematologic ${ }^{2}$ disorders; however, neurologic, ${ }^{3}$ dermatologic, ${ }^{4}$ ophthalmologic, and other disorders are reported. ${ }^{5}$ The surgical resection of the tumor and associated adjuvant therapies often result in an improvement or complete remission of the symptoms. On the other hand, a thymus-related syndrome sometimes develops months or years after the treatment of the thymoma. ${ }^{1}$ Moreover, the recurrence of thymoma may be accom-

\footnotetext{
From the Division of Thoracic Surgery, Department of Cardiac and Thoracic Surgery, ${ }^{\mathrm{a}}$ and Division of Neurology, ${ }^{\mathrm{b}}$ University of Pisa, Pisa, Italy.

Received for publication May 3, 2007; accepted for publication July 9, 2007.

Address for reprints: Marco Lucchi, MD, Division of Thoracic Surgery, University of Pisa, Via Paradisa 2, 56124 Pisa, Italy (E-mail: m.lucchi@med.unipi.it).

J Thorac Cardiovasc Surg 2007;134:1376-8

$0022-5223 / \$ 32.00$

Copyright $\odot 2007$ by The American Association for Thoracic Surgery doi:10.1016/j.jtcvs.2007.07.040
}

panied by recurrence of the originally associated paraneoplastic syndrome, even after many years.

The association of 2 or more paraneoplastic syndromes is rare in any case. We report a unique case of invasive thymoma and 4 thymus-related syndromes occurring in the preoperative setting.

\section{Clinical Summary}

A 43-year-old man with recurrent fever and limb petechiae was admitted to the internal medicine division of our hospital. Serum platelet count was $16 \times 10^{3} / \mu \mathrm{L}$, red cell count was $2.9 \times 10^{6} / \mu \mathrm{L}$, and hemoglobin concentration was $8.2 \mathrm{~g} / \mathrm{dL}$. The diagnosis of pure red cell aplasia and idiopathic thrombocytopenic purpura was made.

The marrow biopsy showed 1) a well-represented granuloblastic group with hyperplastic phenomenon, without morphologic anomalies; 2) a low presentation of red cells with some erythroblastic cells, and 3) anomalies in the distribution of lymphoid cells.

The patient also presented with a rheumatologic disease characterized by intense pain localized at the fingers and arms, which was treated with nonsteroidal anti- inflammatory drugs. The anemia and thrombocytopenia were treated with transfusions.

A standard chest $\mathrm{x}$-ray evidenced the presence of a voluminous mass of the anterior and superior mediastinum prominent on the 


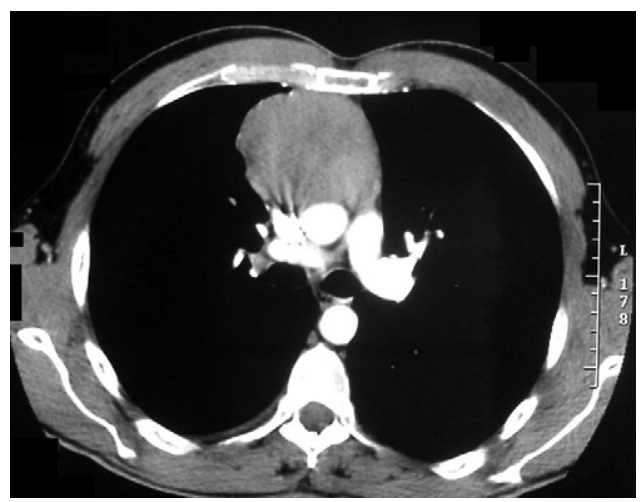

Figure 1. Chest CT scan of the mediastinal mass.

right side. A chest computed tomographic (CT) scan confirmed the presence of an irregular mass $(57 \times 75 \times 100 \mathrm{~mm})$ in the anterior mediastinum, compressing the right vascular structures (Figure 1).

The patient was then referred to the division of thoracic surgery with the clinical diagnosis of mediastinal tumor with red cell aplasia, thrombocytopenia, and undefined rheumatologic syndrome. After the neurologic evaluation, myasthenia gravis was demonstrated with a high titer of acetylcholine receptor antibody.

During the preoperative period, the patient required transfusion of 3 units of platelets and 2 units of red cells. The preoperative blood test results were as follows: platelet count of $35 \times 10^{3} / \mu \mathrm{L}$, red cell count of $3.39 \times 10^{6} / \mu \mathrm{L}$, mean cell volume of $82.4 \mathrm{fL}$, and hemoglobin concentration of $10 \mathrm{~g} / \mathrm{dL}$.

The lesion was radically resected through a median longitudinal sternotomy. During the procedure, another unit of platelets was administered. The postoperative course was uneventful, and the patient did not require any further transfusion.

The pathologic study described a "Thymoma with rich lymphocritical component, extensively infiltrating the mediastinal fat. The capsula is infiltrated in many parts."

A recent pathologic review, according to the new World Health Organization classification, defined the tumor as "Thymoma B2 infiltrating the capsula and the mediastinal fat; Masaoka stage IIB." At the discharge 1 week later, the patient showed the following laboratory values: red cell count of $3.16 \times 10^{6} / \mu \mathrm{L}$, hemoglobin concentra- tion of $9.3 \mathrm{~g} / \mathrm{dL}$, hematocrit level of $26.9 \%$, and platelet count of 372 $\times 10^{3} / \mu \mathrm{L}$. The patient was referred for mediastinal radiotherapy (50 Gy), but after 2 fractions he refused the treatment.

At the 3-month follow-up, the patient's hematologic status was completely recovered. Myasthenia gravis was initially controlled with anticholinesterase and steroid therapy, and then the patient had a complete remission without drugs. The rheumatologic symptoms were still present, and the patient underwent long-term therapy with disease-modifying antirheumatic drugs.

At the last follow-up, 5 years after the operation, the chest CT evidenced the presence of a rounded, solid, 3-cm-wide lesion localized on the right mediastinal pleura (Figure 2).

The mass on the visceral pleura of the superior right lobe was removed by a posterolateral thoracotomy, and hyperthermic $\left(42^{\circ} \mathrm{C}\right)$ intrapleural chemotherapy with cisplatin and epidoxorubicin was performed.

\section{Discussion}

Paraneoplastic syndromes associated with thymomas are often characterized by an underlying autoimmune mechanism. Thymomas are often associated with defects of T-cell maturation, leading to tolerance breakage. ${ }^{1}$

Myasthenia gravis is associated with thymomas in $30 \%$ to $45 \%$ of the cases, sometimes as the first symptom. Pure red cell aplasia is present in $5 \%$ to $10 \%$ of the cases, and the association between thymoma and thrombocytopenia has been observed in a few cases.

In our patient, both of these improved in the immediate postoperative period, emphasizing their strict correlation to the tumor. Although the tumor appeared invasive at the CT, we judged it resectable and the patient not eligible for neoadjuvant chemotherapy because of the hematologic symptom.

Remission of pure red cell aplasia after thymectomy is reported in $25 \%$ to $30 \%$ of cases, but usually it requires some adjuvant therapies such as cyclosporine and antithymocyte globulin. ${ }^{2}$

The rheumatic symptom slightly decreased on the second postoperative day, but 1 month from the removal of the pleural recurrence, the pain was still present and the specific therapy (steroids and disease-modifying antirheumatic drugs) is ongoing.

Although some thymus-related disorders in patients with thymomas are well described in the literature, the presence of 4 syndromes in the same patient is unique and to our knowledge has never been reported.

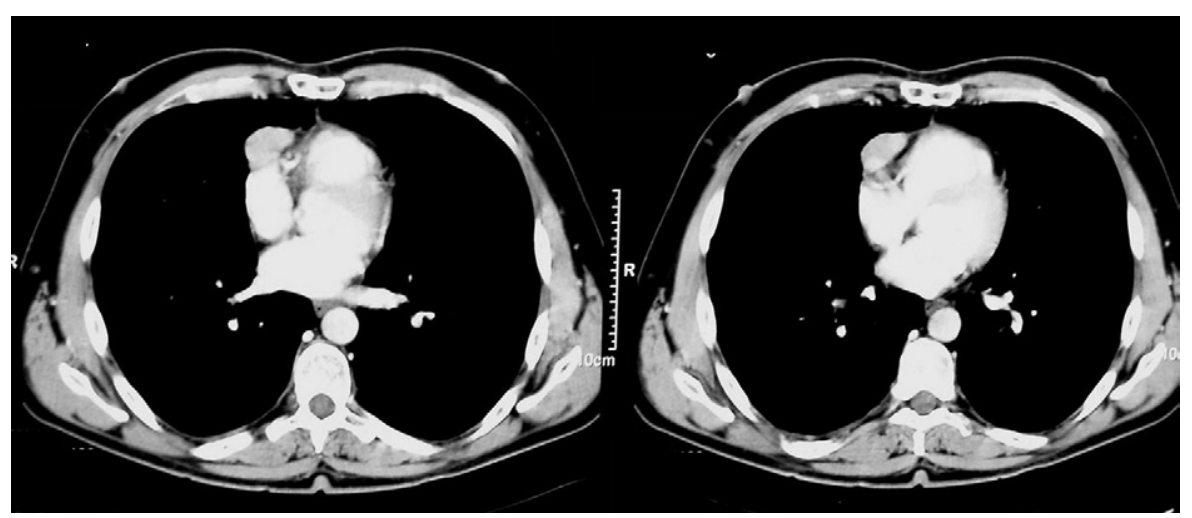

Figure 2. Chest CT scan 5 years after the operation showing the presence of a right pleural recurrence (white arrow). At the time of thoracotomy, the lesion localized on the visceral pleura of the upper right lobe. 
It is advisable for physicians to exclude the possibility of a paraneoplastic thymoma-related syndrome whenever a patient with a thymoma does not have well-defined complaints.

\section{References}

1. Evoli A, Minicuci GM, Vitaliani R, Battaglia A, Della Marca G, Lauriola L, et al. Paraneoplastic diseases associated with thymoma. J Neurol. 2007;254:756-62.
2. Thompson CA, Steensma DP. Pure red cell aplasia associated with thymoma: clinical insights from a 50 year single institution experience. Br J Hematol. 2006;135:405-7.

3. D'Avino C, Lucchi M, Ceravolo R, Mussi A, Malandrini A, Annunziata $\mathrm{P}$, et al. Limbic encephalitis associated with thymic cancer: a case report. J Neurol. 2001;248:1000-2.

4. Leyn J, Degreef H. Paraneoplastic pemphigus in a patient with a thymoma. Dermatology. 2001;202:151-4.

5. Yamada G, Ohguro H, Aketa K, Itoh T, Shijubo N, Takahashi H, et al. Invasive thymoma with paraneoplastic retinopathy. Hum Pathol. 2003 34:717-9. 